\title{
MANAGEMENT THE SAFETY OF EXPLOITATION OF THE ROTATION MECHANISM IN A SELF-PROPELLED CRANE
}

doi: $\quad 10.2478 /$ czoto-2019-0079

Date of submission of the article to the Editor: 09/11/2018

Date of acceptance of the article by the Editor: 20/12/2018

\author{
Marek Krynke ${ }^{1}$ - orcid id: 0000-0003-4417-1955 \\ Alan Vaško ${ }^{2}$ - orcid id: 0000-0002-3937-2691 \\ ${ }^{1}$ Czestochowa University of Technology, Poland, marek.krynke@wz.pcz.pl \\ ${ }^{2}$ University of Žilina, Slovakia
}

\begin{abstract}
The article analyzes of the load capacity of the rotation mechanism of the boom arm sub-assembly for a self-propelled crane. The uneven flexibility of systems supporting structures of the machine was taken into account in the identification of the load. The consideration are illustrated by the example slewing bearing from selfpropelled crane. FEM method was used for calculations. The basic problems of construction of numerical model were discussed. Sample calculations of bearing carrying capacity has been done taking into account flexibility of bearings supporting structures, which also allowed to define the internal load distribution in the bearing. On example of the supporting structure of the mobile crane DST 5050 the internal load distribution in the crane bearing at different positions of the crane machine body were defined. During the rotation of the crane body priority angels were indicated. It has been shown that the deformations of the supporting frames are so large that they significantly change the distribution of forces transmitted by the individual bearing rollers.
\end{abstract}

Keywords: stability of cranes, slewing bearings, bearing capacity

\section{INTRODUCTION}

Mobile boom cranes are used throughout the world to perform important and dangerous manipulation tasks. Given their mobility, these types of cranes can quickly be moved into position. In most cases, their base is then fixed and stabilized before they start lifting heavy materials. The usefulness of these cranes can be greatly improved if they can utilize their mobile base during the lifting and transferring phases of operation (Maczynski and Wojciech, 2003). This ability greatly expands the workspace by combining base motion with the rotation, lifting, and luffing motions. Of course, mobile cranes lose some stability margin when a payload is attached. The stability is further degraded when the payload swings. This thesis presents a carrying capacity study of mobile cranes (Liang et al., 2012).

As a first step, a static carrying capacity analysis of a boom crane is conducted in order to provide basic insights into the effects of the payload weight and crane 
configuration. Crane stability is characterized by the maximum payload it can carry throughout the workspace. A crane is regarded as stable as long as all wheel contact forces are positive. The influences of the boom attachment point and the boom weight are investigated (Kania et al., 2012).

Mechanisms of the rotation (Fig.1) for crane are most often constructed with using rolling slewing bearings. They are these are sub-assemblies of machines that transferring the whole of the loading resulting from the work of machine (Kania, 2012). Their particularities features that cause big load capacity at the relatively clenched construction and comparatively small dimensions, not only in classical machines and devices, as diggers, of all kinds cranes and different building machines, military vehicles are finding application. It is also applied in wind power stations, track vehicles and many different devices (Smolnicki, 2013).

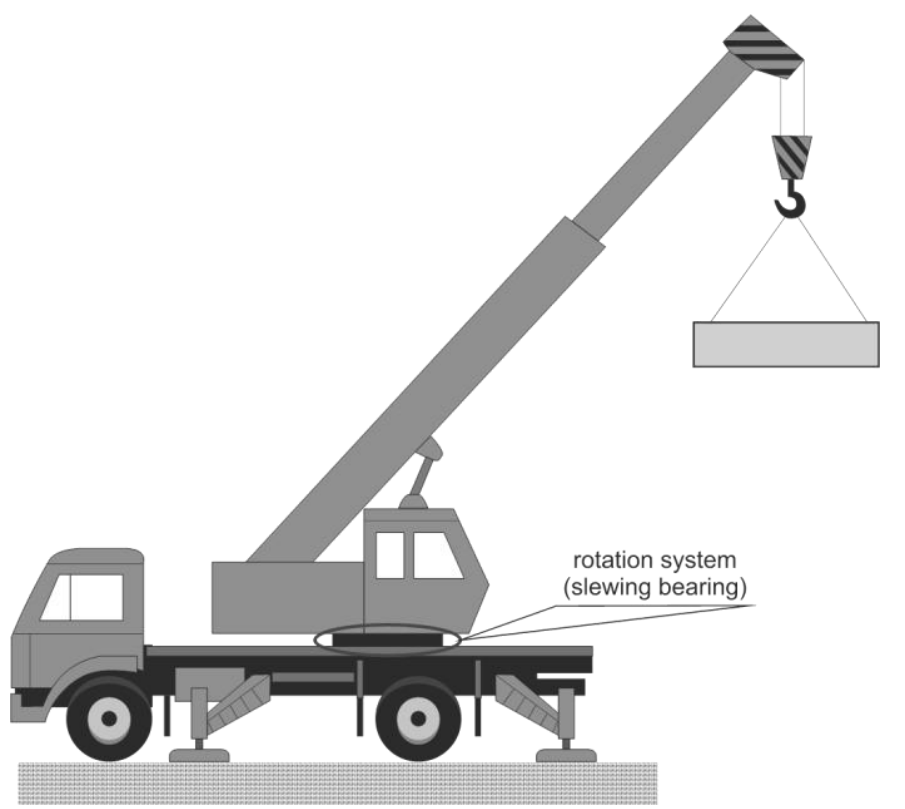

Fig. 1. Mechanism of the rotation for crane

The carrying capacity of slewing bearings usually limits maxi-mum value of outside burdens for the designed device, and correct its determining is the important part of calculations (Kania and Krynke, 2013). Slewing bearings are usually selected extremely, namely this way so that their work is on the breaking point (Smolnicki et al., 2017). It requires supplementing the move from the assembly, the permanence for determining resistances with additional criteria from careful and accurate calculations of their functional parameters: assembly, durability, resistance to motion (Kania and Śpiewak, 2014). Important is fact that in many devices damaging, or destroying the bearing, can cause catastrophic effects accidents. Moreover it requires a long time excluding the device from the utilization and is generating higher costs of repair (Ulewicz, 2016; Mazur, 2018).

\section{MOBILE CRANE STABILITY}

The concept of stability derives from the conditions of the balance of a perfectly rigid solid, freely supported in the gravitational field. It is assumed that the crane is stable when the algebraic sum of the fixing moments is greater than the sum of the overturning moments (Liu et al., 2018). For the tested model of a self-propelled crane, 
fixing moments should be taken that increase the support reactions of non-lying on the hypothetical edge of the overturn. Obviously, the overturning moments will be those that reduce the value of these reactions. These moments should be calculated taking into account the load on the crane (Mielczarek and Knop, 2018).

The mentioned tipping edges are lines in relation to which the stability is lost (depending on the specified crane setting). Depending on the type of chassis (or mounting method) of the crane, these edges are as follows:

- tracked chassis - the tipping edges are the axles of the first pair of rollers at the front and the drive wheel at the rear for the longitudinal position of the crane and the symmetry axes of the rollers cooperating with the track plates at the transverse position,

- wheeled chassis, work without supports (if possible) - the tipping edges are both in the longitudinal and lateral position of the wheel symmetry axes,

- wheeled chassis, work with supports - the tipping edges run in this case through the centers of the support legs (Fig. 2a).

In addition to stability, the critical element of the crane is a slewing bearing that acts as a turning node for the boom. Its load capacity often determines the load capacity of the entire device (Śpiewak, 2016). Therefore, improper operation of the crane may damage the bearing and contribute to the loss of boom stability (Fig. 2b) (Krynke and Mielczarek, 2016).

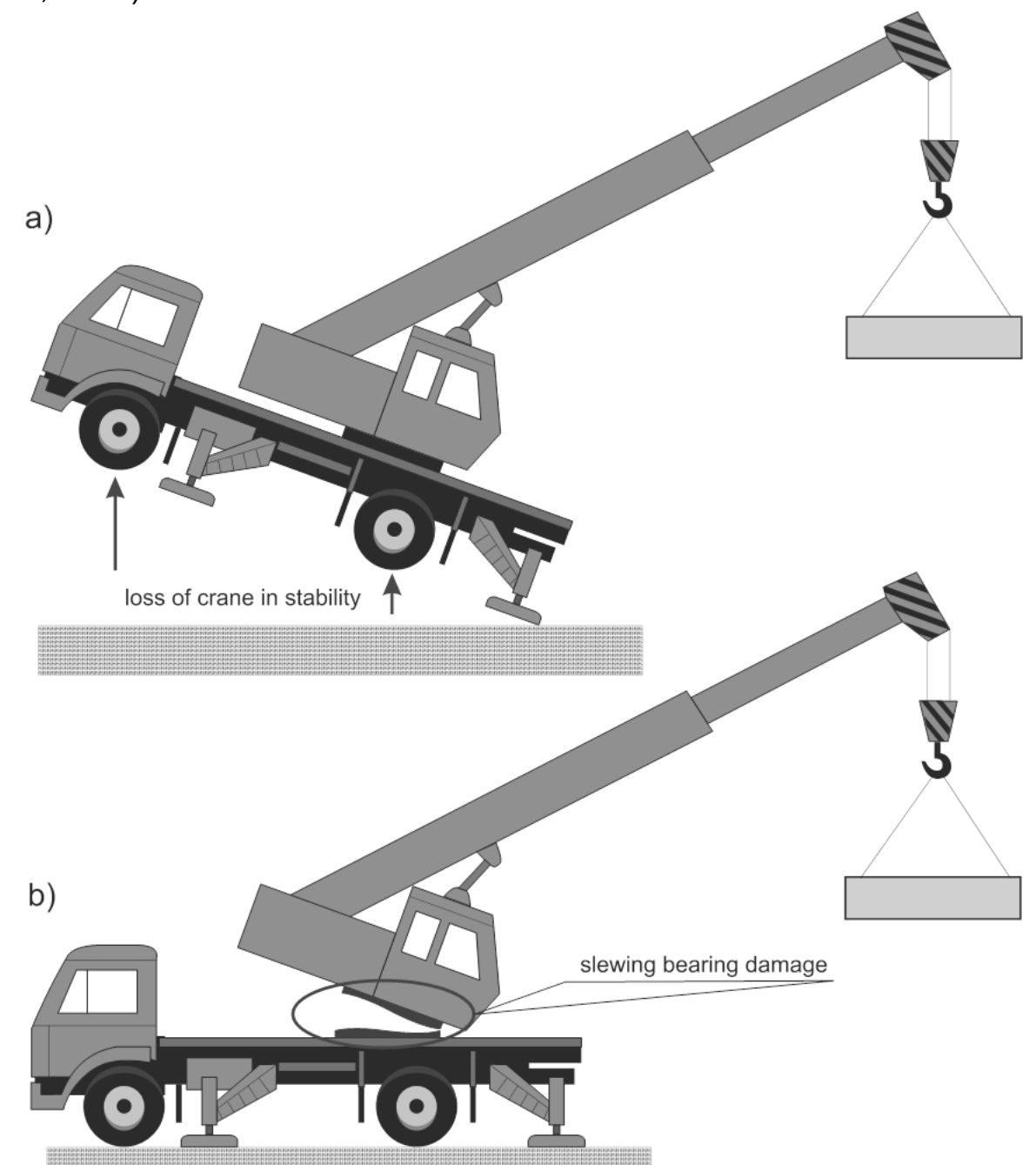

Fig. 2. Mobile crane stability: loss of crane in stability (a), slewing bearing damage (b) 


\section{ROTATION MECHANISM OF JIB ARM OF A CRANE}

The object of considerations is the slewing ring bearing used in the rotation mechanism of the DST - 5050 self-moving crane. In the case of the above crane, a cross roller bearing with a rolling diameter of $1400 \mathrm{~mm}$ and catalog symbol 1.KW.Z.T.50.1390.3.3.01 (Fig. 3) was used. The crane load characteristics are shown in Figure 4.

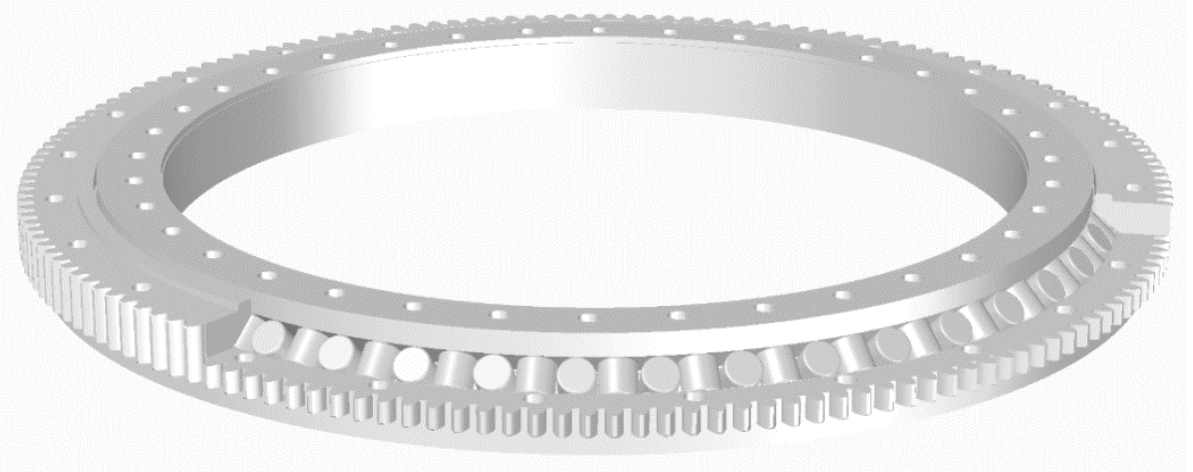

Fig. 3. Single-row cross roller slewing bearings

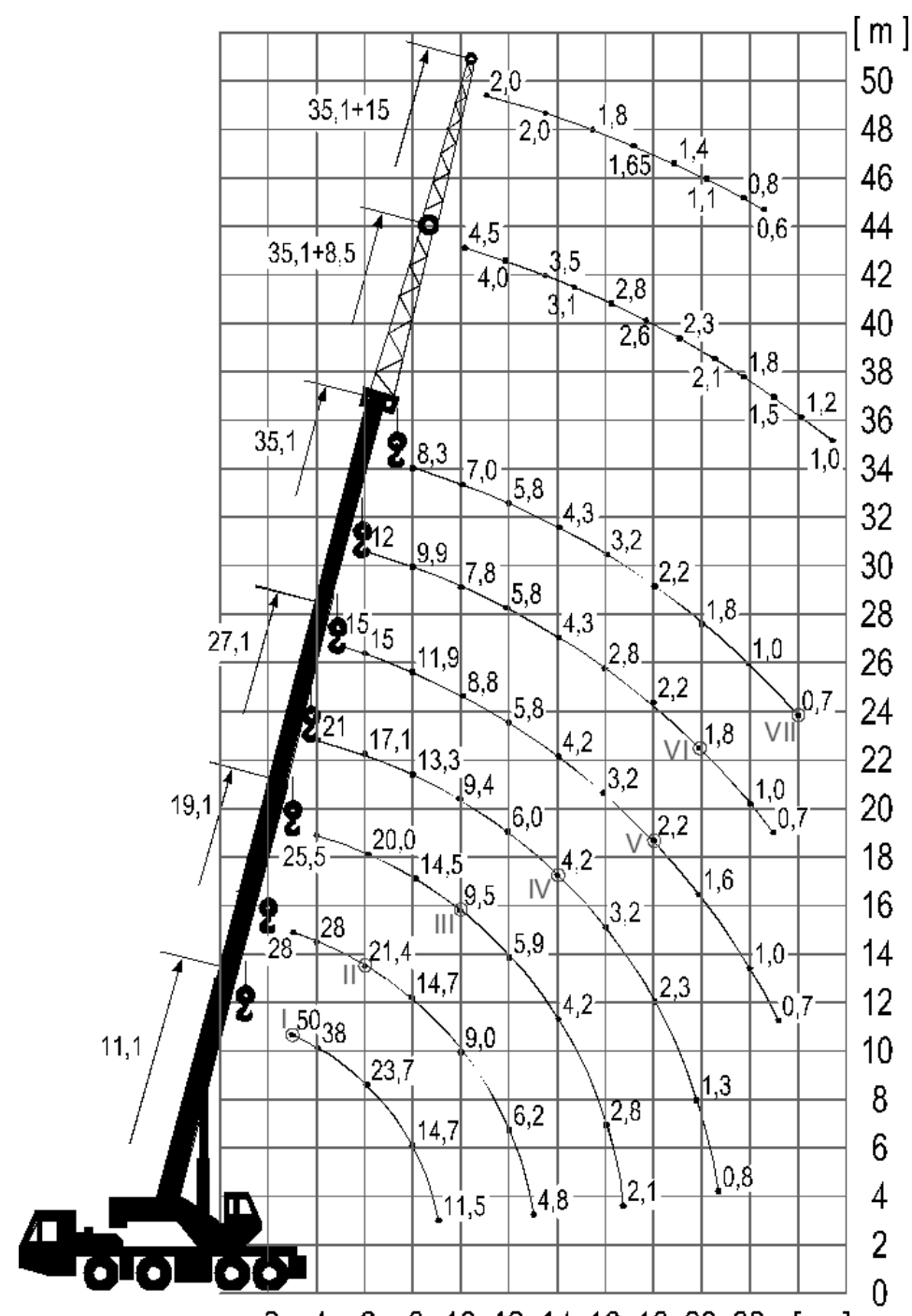

$\begin{array}{lllllllllllll}2 & 4 & 6 & 8 & 10 & 12 & 14 & 16 & 18 & 20 & 22 & \text { [m } 1\end{array}$ $\mathrm{m}]$ 48 46 42 40 36 34 $(32$ 8

Fig. 4. Characteristics of the mobile crane load (DST - 5050) 


\section{COMPUTATIONAL MODEL}

The ADINA (2009) software was used to build the numerical model. The bearing rings and frames of the body and chassis were discredited by eight-nodes solid elements of 3D-solid type (Yu, 2017). Teeth of outer ring, holes for the bolts and small constructional details were omitted in the model of a bearing. Contact conditions were defined between adequate surfaces of the bearing rings and surfaces of its mounting (Kania et al., 2016; Wang et al., 2017).

The built model enables rotation of the chassis in relation to the body at arbitrary angle $(\theta)$ in a range of $360^{\circ}$. The load was imposed on the additional rigid rods connected to the axes of holes where pivots of extension arm and servo-motor were supported.

The values of the forces were calculated using an appropriate algorithm which allows the simulation of an external load. The mesh of finite elements of the model is shown in Figure 5.

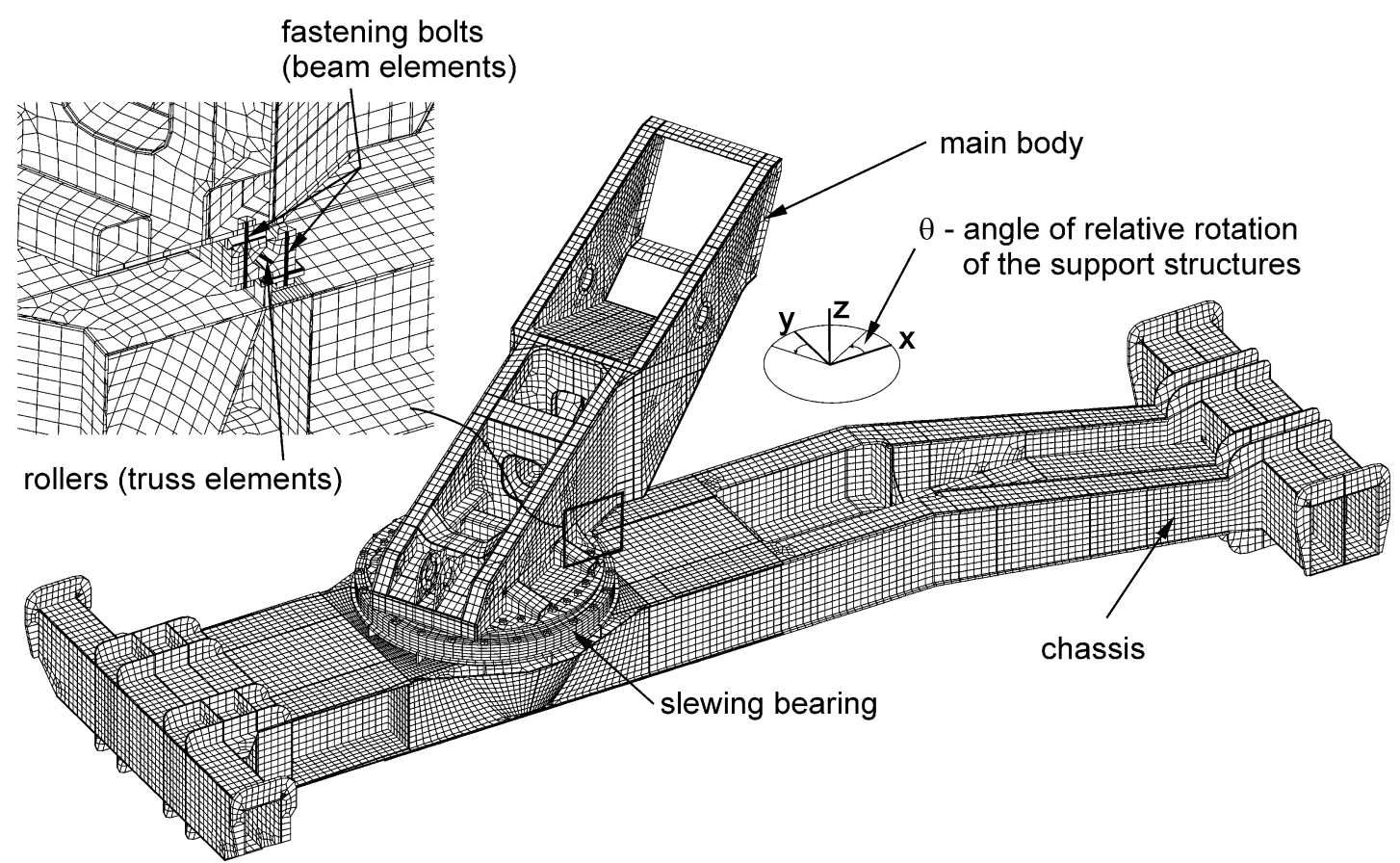

Fig. 5. The mesh of numerical model of crane's support structures together with slewing bearing

\section{ANALYSIS OF THE LOAD CAPACITY OF THE ROTATION MECHANISM FOR CRANE}

The computations of the real local capacity for nineteen positions of the body towards the chassis with the pitch $10^{\circ}$ in the range to $180^{\circ}$, due to symmetry of the chassis and body, were carried out using the worked out numerical model. In the case of nonsymmetrical constructions, the analysis should be carried out in the range $360^{\circ}$.

Every computation of the local characteristic represents separate cycle of computations. The local capacity was computed for ten values of the load in the range from zero (the load of bearing with axial force $Q$ ) to infinity (the load of bearing only with tilting moment $\mathrm{M}$ ). The consecutive points of bearing characteristic were obtained. It should be noticed that load with "clear" axial force as well as with "clear" tilting moment is not realized in practice. They are computed only to determine extreme points of bearing characteristic. The capacity in every point of characteristic 
is computed by iteration. The computations are carried out until, rolling elements reaches limiting value in the one of the rows. The results of computations are presented in graphical in Fig. 6.

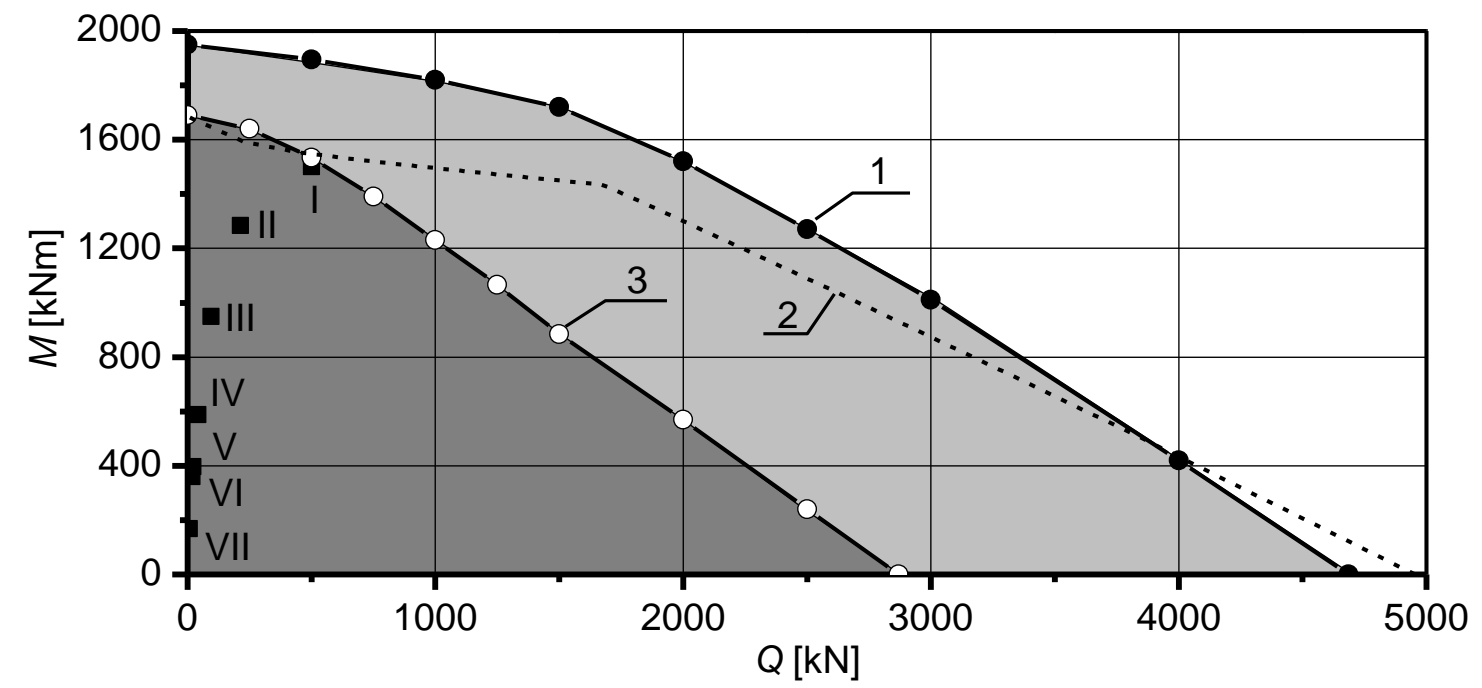

Fig. 6. Diagrams of the bearing characteristics: 1 - catalogue characteristic computed with use "flexible rings" method, 2 - catalogue capacity of bearing computed with use "rigid rings" method, 3 - local characteristics for angle $\theta=50^{\circ}$ of rotation of the crane body relative to the chassis

Catalogue characteristics of bearing, received by usage of two methods: "rigid rings" and "flexible rings", are additionally shown in Fig. 6. Distinct differences of local capacities in relation to catalogue capacities as well as local capacities in respect of each other are noticeable. The final results of computations, it means local capacity of a bearing for angle 50 , is marked with line 3 .

Study of the internal load distribution in the bearing for the different positions of the body relative to the chassis working machine allows to evaluate the quality of the support subassembly, and identify critical points in the design of the chassis.

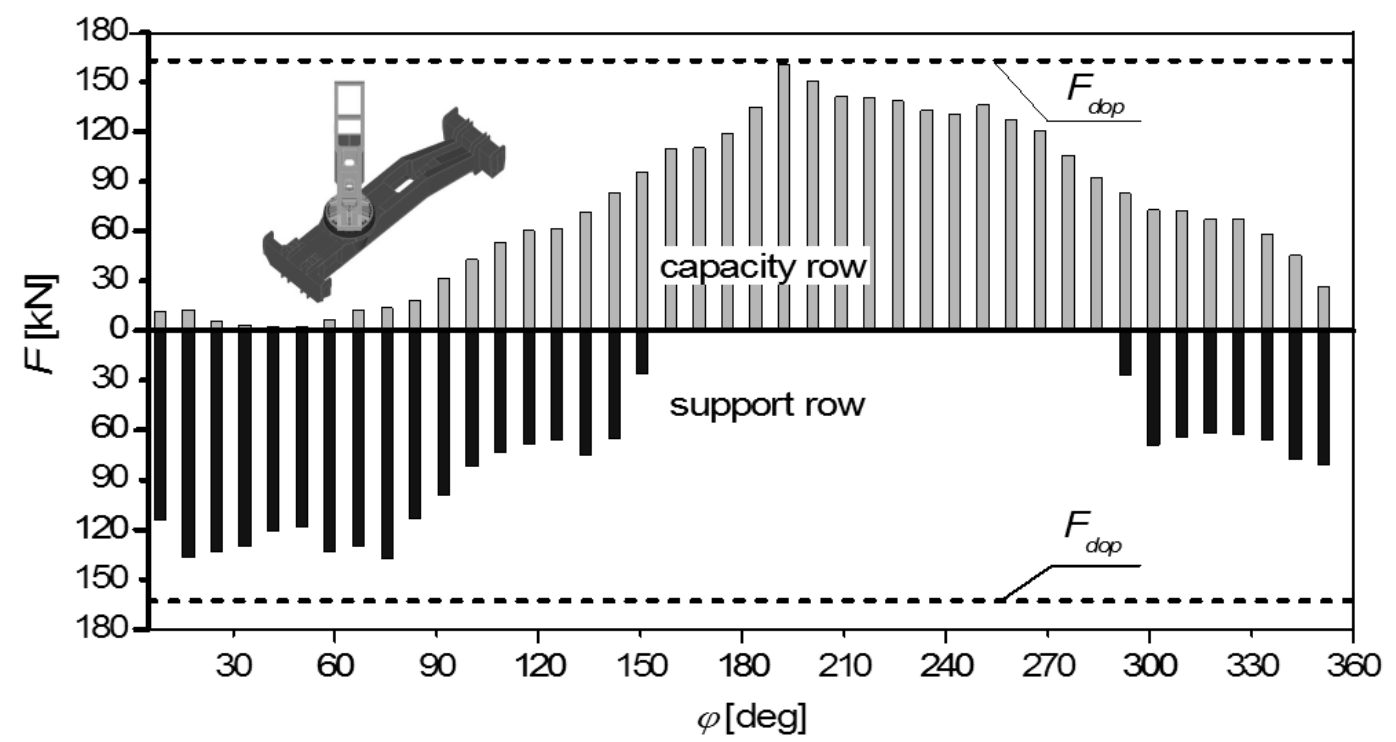

Fig. 7. Distribution of internal load in a cross-roller bearing for critical position $\left(\theta=50^{\circ}\right)$ of the support subassembly with a load of 50 tons and a jib length of 3 meters 
Figure 7 shows a graph showing the load of individual rolling elements along the circumference of the bearing, with the chassis position for a crane load of 50 tons on the $3 \mathrm{~m}$ arm. In this graph, the inequality of the internal load distribution is visible. At the points of placing the supports and at the points of load introduction into the annular girder, i.e. the "hard" points of the load are over a dozen percent higher than between them.

In Figure 8 shows the maximum load as a function of the rolling elements of the position of the load jib. The presented results can be seen that the highest load bearing race are for body position angle of about $50^{\circ}$.

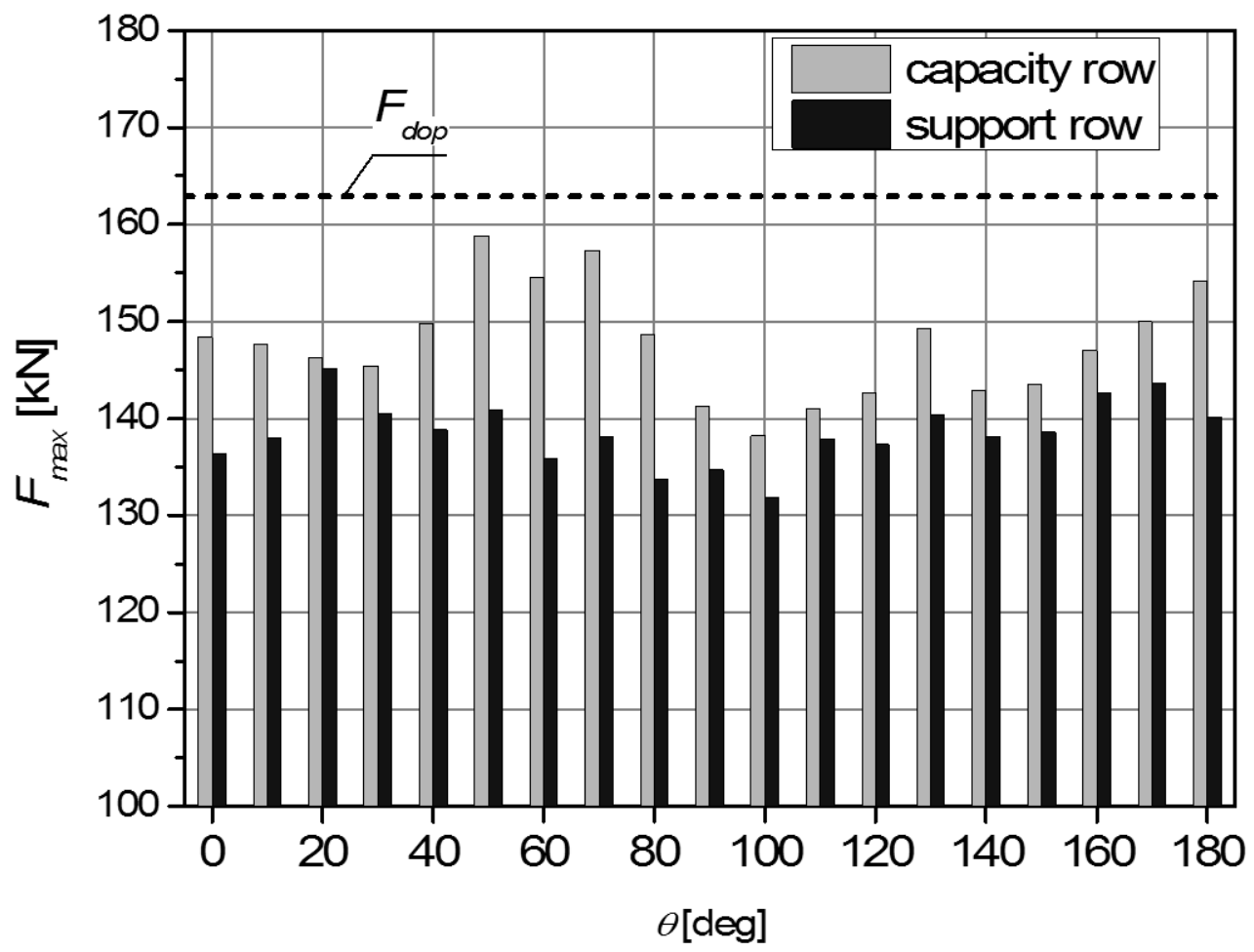

Fig. 8. Maximum load of bearing rolling elements for different positions of the support subassembly with a load of 50 tons and a jib length of 3 meters

\section{SUMMARY}

The real bearing capacity of the slewing bearings fixed in a machine with a complex shape of supporting structures is definitely lower than the catalog bearing capacity. Differences in bearing capacity for different machine positions are also important. This is due to the uneven distribution of the internal load in the bearing.

The presented FEM model of a self-propelled crane allows to determine the impact of deformability of supporting structures and unevenness of their susceptibility to load of rolling elements in a cross bearing.

The analyzed bearing for an existing self-propelled crane is a heavily loaded bearing. For the maximum load on the crane and selected body positions, the load on some rollers takes limit values. Even $25 \%$ of the catalog load capacity reserve (Figure 6) does not compensate for the effects of deformation of load-bearing structures. Therefore, when designing the structure of the load-bearing frames of the machine, it is necessary to carry out an in-depth analysis of not only the dimensions of the bearing, but also the rigidity of the supporting frames and the screw connections of individual assemblies. 


\section{REFERENCES}

Kania, L., 2012. Zagadnienia lokalne w numerycznym modelowaniu łożysk tocznych wieńcowych. Wydawnictwo Politechniki Częstochowskiej, Częstochowa.

Kania, L., Krynke, M., 2013. Computation of the general carrying capacity of slewing bearings. Engineering computations, 30, 1011-1028.

Kania, L., Krynke, M., Mazanek, E., 2012. A catalogue capacity of slewing bearings. Mechanism and machine theory, 58, 29-45.

Kania, L., Śpiewak, S., 2014. Influence of radial forces on change of friction torque in twin slewing bearing. Machine Dynamics Research, 38, 121-131.

Kania, L., Spiewak, S., Pytlarz, R., 2016. The modification of the raceway profile in the double row slewing bearing. Journal of KONES, 23, 139-146.

Krynke, M., Mielczarek, K., 2016. Analysis of causes and effects errors in calculation of rolling slewing bearings capacity. Production Engineering Archives, 12, 38-41.

Liang, J., Chen, G.H., Wang, X.H. 2012, Discussion on fault evolution processes of slewing bearing for crane. Journal of Safety Science and Technology, 8, 201 12412.

Liu, R., Wang, H.,. Pang, B.T., Gao, X.H., Zong, H.Y., 2018. Load distribution calculation of a four-point-contact slewing bearing and its experimental verification, Experimental Techniques. 42, 243-252

Maczynski, A., Wojciech, S. 2003. Dynamics of a mobile crane and optimization of the slewing motion of its upper structure, Nonlinear Dynamics. 32, 259-290.

Mazur, M., 2018. Analysis of production incompatibilities and risk level in series production of assembly elements for the automotive industry. MATEC Web of Conferences, 183, 1-4.

Mielczarek, K., Knop, K., 2018. Assessment of production processes functioning in the case of air bag production. MATEC Web of Conferences 183, 1-6.

Smolnicki, T., 2013. Wielkogabarytowe toczne węzły obrotowe. Zagadnienia globalne i lokalne. Oficyna Wydawnicza Politechniki Wrocławskiej, Wrocław.

Smolnicki, T., Pękalski, G., Jakubik, J., Harnatkiewicz, P., 2017. Investigation into wear mechanisms of the bearing raceway used in bucket wheel excavators. Archives of Civil and Mechanical Engineering, 17, 1-8.

Śpiewak, S., 2016. Methodology for calculating the complete static carrying capacity of twin slewing bearing. Mechanism and Machine Theory, 101, 181-194.

Ulewicz, R., 2016. Influence of selected technological factors on fatigue strength. Czasopismo Techniczne, Mechanika Zeszyt 3-M, 10, 9-14.

Wang, H., He, P., Pang, B. Gao, X., 2017. A new computational model of large threerow roller slewing bearings using nonlinear springs. Journal of Mechanical Engineering Science, 231, 3831-3839.

Yu, Y.H., Lee, B.R., Cho, Y.J., 2017. New load distribution method for one-row slewing ball bearing considering retainer force. International Journal of Precision Engineering and Manufacturing, 18, 49-56. 